\title{
INTRODUCTORY ADDRESS
}

\author{
By SIR ROBERT HADFIELD, Bart., D.Sc., D.Met., F.R.S.,
}

President of the Faraday Society.

\section{SECTION I.-INTRODUCTION.}

As the result of some suggestions I made several months ago to the Council of the Faraday Society, it was arranged to hold this present Symposium on "The Microscope and its Applications." The Royal Microscopical Society (Mr. J. W. Barnard, President); the Optical Society (Professor F. J. Cheshire, President); and the Photomicro graphic Society (Mr. F. Martin Duncan, President) all most cordially approved and agreed to co-operate with us. In view of the fact that the objects of the Faraday Society, as set forth in its Constitution, are not only to promote the study of Electrochemistry, Electrometallurgy, Physical Chemistry and Kindred Subjects, but also Metallography this Symposium is specially appropriate. It is only, or at any rate chiefly, the last named Branch of Research-Metallography-my own remarks are meant to cover, that is, I do not pretend in this Address to deal with the Work of the Microscope as employed by the Geologist, the Zoologist, the Biologist, and other Branches.

During the preparation of this Address I found the interesting frontispiece of the Book by George Adams, "ESSAYS ON THE MICROSCOPE." This was published July 1st, 1787, and contains a Practical Description of the Most Improved Microscopes, revised by Frederick Kanmacher, F.L.S., 1798. I thought this illustration particularly appropriate to form the frontispiece to this present Address of mine. The quaint wording at the foot of the Engraving

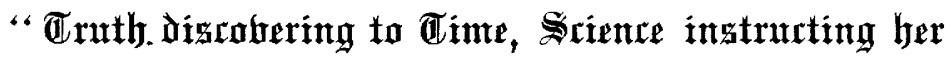 (Chilloren in the Improbements on the eftirromerape,"}

well describes the object of our present Symposium.

As regards the modern application of the Microscope including that to Metallography, below is a portion of the preface to Monsieur Félix Robin's Work "Treatise on Metallography," contributed by Professor F. Osmond, who did so much for Metallurgy, and from 
whose work we are to-day greatly benefiting. Robin has, alas, himself passed away during the Great War, gloriously devoting his life on the Field of Battle on behalf of his Country. I make no apologies for referring to this tribute to the Metallographist and for quoting in full the wise words of Osmond. These are well worthy of consideration to-day, and the reasons given by him will, I trust, cheer many an author and many a worker in the fields of research.

Osmond said: "To write a treatise on a branch of Science in process of active development is an arduous task, especially when the author is not a professor and the book not the natural synthesis of the course. It is also a thankless task, for the work of to-morrow will amplify and correct that of to-day. In a few years' time, too, the old edifice must be rebuilt because the new generation no longer deems it sufficiently comfortable in its old form. We ought, therefore, to be indebted to those who have the courage-which I have always lacked-to collect and collate scattered material. Those who continue the work are thereby saved the trouble of lengthy visits to libraries and the search for documents of sometimes questionable value disseminated in the periodicals of all civilised countries. But M. Robin's book is not a mere compilation. The author, whose numerous papers have evoked the attention of, and have been the subject of numerous awards by, the British Iron and Steel Institute and others, has been working whole-heartedly for some years past in the direction of extending our knowledge of Metallography and its kindred Sciences. His contributions to this Science have been most useful, and he is thus in a position to enrich the present treatise by his personal experience and minute observations, to the great benefit of those who will follow him."

"La science est un pays plein de terres désertes;

"Tous les jours nos auteurs y font des découvertes.

"Mais ce champ ne se peut tellement moissonner,

"Que les derniers venus n'y trouvent à glaner."

\section{WORK OF THE VARIOUS Societies TAKING PART}

\section{IN THIS SyMPOSIUM.}

The Faraday Society.-Turning to the work of each of the Societies taking part in this Symposium, I deal with that of the Faraday Society in a separate paper presented to this Symposium, entitled "The Work of the Faraday Society and a brief Reference to Michael Faraday." I will therefore not add anything further here. (See Appendix II, p. 254).

Royal Microscopical Society.-The Royal Microscopical Society was established in 1839. The late Dr. H. C. Sorby, F.R.S., of Sheffield, the Founder of Modern Metallography and of whom a portrait is given in Fig. 1, was President of this Society in 1876 and 1877. The famous Microscopist, Dr. W. Dallinger, F.R.S., of whom a portrait is given in Fig. 2, and who lived in Sheffield for a number of years, was also President, in the years 1884-7. 
Amongst other Past Presidents of this important Society have been Sir Richard Owen, 1840; Edwin Lankester, 1858 ; John Thomas Quekett, 1860 ; Lord Avebury, 1907 ; Sir Edwin Ray Lankester, 1909 ; Prof. H. G. Plimmer, 1911 ; and to-day Mr. J. E. Barnard.

It was in November, 1866, that Mr. Secretary Walpole notified the President that Her Majesty had been graciously pleased "to command that the Society shall be styled the Royal Microscopical Society."

Singular to say, notwithstanding his early work in 1857-1863, Dr. Sorby, even in his own Presidential Addresses in 1876-1877 to the Royal Microscopical Society, made no reference to the use of the Microscope for Metallurgical Research. Apparently, he himself had not then applied his method of study, but the germ was there waiting to be developed. Professor W. G. Fearnsides has pointed out in his interesting account of Sorby's lifework in the first Sorby Lecture delivered before the Sheffield Society of Engineers and Metallurgists in 1914, "On some Structural Analogies between Igneous Rocks and Metals," that it was in the year 1885, by the use of Lenses of high resolving power and comparatively large magnification, Sorby first saw the true composite nature of the "pearly constituent" of Steel as an aggregate of parallel plates. This discovery was the earliest recognition of the formation of crystals from a solid solution, and may be regarded as the crowning achievement of his microscopical research. He announced this discovery to the Iron and Steel Institute in 1886, and in 1887 presented to the same Institution his historical Paper on "The Microscopical Structure of Iron and Steel," which gave a full account of his methods and the results he had obtained.

A well-known American writer, in a biographical sketch of Sorby published in "The Metallographist" for April, 1900, stated: "Whatever has been accomplished since in Microscopic Metallography has been done by following in his footsteps. To Dr. Sorby, and to him alone, is due the pioneer's honour."

I had at first intended to include in this Address my remarks regarding the great work performed by Sorby for "The Metallographist." In view, however, of the importance of the subject, and that some of our younger members may not be aware of the facts, I have thought it best to embody and present these in a separate short communication entitled "The Great Work of Sorby."

Optical Society.-As regards the Optical Society, which now has its Headquarters at the Imperiai College of Science and Technology at South Kensington, this was founded in 1899, its first President being Mr. W. H. E. Thornthwaite, F.R.A.S. Subsequent Presidents have been Dr. R. M. Walmsley, Professor Silvanus Thompson, Dr. W. Rosenhain, Sir Richard Glazebrook, Sir David Gill, and to-day Professor Cheshire, C.B.E., who did such excellent work in the War.

Photomicrographic Society.-The Photomicrographic Society was founded in 1911 by a small band of Microscopists and Photographers, including Fellows of both the Royal Microscopical and Photographic Societies, having for its objects, to quote from its Rules, " the study 
of Photomicrography and the discussion and demonstration of any subjects of interest concerning it." From the first the Society was a success, as evidenced by continual increase of Membership, and this is perhaps due to the wide field in Research, Engineering, Natural History, Industrial and other Processes, in which the Microscope is essential. This is also shown in the diverse nature of the subjects in which individual members are specially interested, but who alike have to record their observations by Photography. Others again are interested purely in the optical equipment of the Microscope and the special problems presented to the photomicrographic worker. The essential importance of correct microscopic technique, especially proper illumination to obtain a correct image, has always been recognised, and great attention has been paid to the mechanical side, as shown by apparatus designed and built by several members and exhibited from time to time.

Mr. F. Martin Duncan now occupies the Presidential Chair, and Mr. J. E. Barnard was President in 1915-16. A Medal is awarded annually, for the best results in Photomicrography from both the microscopical and photographic point of view.

The Society meets twice monthly at King's College, and has papers on the many subjects in which the use of the Microscope is essential, together with other meetings of a less formal character for discussion, exhibition of photomicrographs, and apparatus connected with Photomicrography.

For the foregoing information I am indebted to the Honorary Secretary and Treasurer, Mr. J. G. Bradbury, who has done so much good work on behalf of this useful Society.

British Science Guild.-The Committee on the Microscope appointed by this Body, with its Chairman, Dr. Walmsley, have also been kind enough to give much useful help with regard to our Symposium.

It will be seen therefore that the Faraday Society has been successful in enlisting the co-operation and aid of the various special Societies who are also immediately interested in improving Research Work in Microscopy. are :-

OBjects of THE Symposium.-The objects of the Symposium

(a) Improvement in the technique of the Microscope itself, including its manufacture.

(b) Improvement in Lenses including Eye-pieces and Objectives of High Power.

(c) Improved application of the Microscope for Research in Ferrous and Non-Ferrous Metallurgy.

With these objects all will be in agreement, and if as a result of this Symposium they are successfully carried out and attained, as I am confident will be the case, our gathering will be not only 
noteworthy, but will prove to be of great service to those interested, in our own Country, America, and elsewhere.

PRESENT AND Future Work--As regards the particular direction in which Metallurgists should look in the future for further help from the Microscope, may I suggest that one of the objects we ought to have in view should be to obtain increased knowledge from examinations at higher magnifications, that is to say, 5,000 , 8,000 and still higher. This may seem ambitious, and I may be wrong as to the value of the knowledge to be so obtained, but I hope not. If there is anything in my belief, a wide vista opens out for further Research Work.

I am contributing along with Mr. T. G. Elliot, F.I.C., a special paper on this important aspect of the subject, entitled "Photomicrographs of Steel and Iron at High Magnification," which I hope will be of interest to our members.

In the past both in England and in America there has been far too much dependence on Germany and Austria for the supply of the best type of Microscope, including constructional details, and high-quality Objectives and Eye-pieces. It is most desirable that in future this situation should be avoided. Forewarned is forearmed, and every possible means must be taken in a fair and open manner to remedy this situation by private enterprise and research, and if necessary by Research Associations aided by the grants allocated by Parliament for such purposes.

To show that it is of the highest importance that this Country should be independent of foreign aid in its supplies of this nature, it may be added that had it not been for the enterprise of just one British Firm with regard to the supply of Optical Glasses at the outbreak of War, we might have been absolutely stranded in the supply of the necessary products, both for apparatus and glassware, so essential in sighting and other instruments of observation used in Modern Warfare.

By these remarks I do not wish to disparage the work of those who until recently have been Enemies, and who in the past wisely equipped themselves by means of Apparatus and Appliances of all kinds as well as by encouraging scientific development. Good work proceeding from any nationality stands fast for all time. Let us, however, now learn the lesson and benefit from the experience gained by us during the War at such bitter cost. It has to be admitted that our Instrument Makers were then necessarily largely employed in other directions and were unable to cater for the requirements of the Microscopist. They could not therefore devote the time so essential for improving not only the mechanical but the optical details of the Microscope, including its Objectives and Eye-pieces. Notwithstanding the many advances made during the War by the Chemist, the Electrician, the Metallurgist, the Engineer, and others, no special claim can be made that much progress has been made by the Microscopist. As far as can be gathered, the methods and appliances now used do not show great advance on those prior to the War. In saying 
that it is not meant to indicate that knowledge has not been accumulated and that, for example, we shall in the future be dependent upon foreign supplies as in the past; it is hoped quite the contrary. It is one of the main objects of this Symposium to bring forth and prove that all these requirements can and will be met by the AngloSaxon, or at any rate that this will be possible in the immediate future.

It should be added that there stands out very prominently in this connection the important work done on behalf of Glass Technology by Sir Herbert Jackson, K.B.E., to whom we are greatly indebted, and who will give us an important Address this evening.

Reference should also be made to the excellent work carried out on this subject by the National Physical Laboratory, where systematic work on the attack of various refractory bodies by molten glass under carefully standardised conditions has been continued, together with work on the production of crucibles increasingly resistant to such attack. Progress has been made in the application of fused zirconia as a lining for crucibles. In the course of this work special phenomena have been observed in the attack which occurs in some cases at the bottom of the crucible, and in others, at the level of the surface of the glass. These phenomena have been studied by means of experiments on the mode of solution of such substance as wax, naphthaline and plaster-of-paris in ordinary solvents at room temperature where the phenomena could be observed. Most of the features met with in the attack of molten glass on crucibles have been reproduced in such experiments, and a method of preventing the worst features of such attack has been tried and found successful in the model experiments. In addition reference should be made to the valuable work done by the Society of Glass Technology at the University of Sheffield, in which Dr. W. E. S. Turner, the honorary secretary, has played so important a part.

It is certainly most necessary that we should not be behind but abreast of our Foreign competitors in the making of Microscopes and Lenses or their use. One of the prominent objects in holding the Symposium is to arouse still more interest in the advancement of this work.

\section{SECTION II.-HISTORY OF THE MICROSCOPE.}

\section{Ancient Times to 1600 A.D.}

If the Microscope is considered as an Instrument consisting of one Lens only, it is not at all improbable that it was known to the Ancients, and even to the Greeks and Romans. The minuteness of some of the pieces of workmanship of the Ancients would appear to indicate that they must have been executed by the use of Magnifying Glasses. Many passages in the Works of Pliny, Plutarch, Seneca, and others clearly indicate this.

There is reason to believe that the magnifying power of transparent media with convex surfaces was known very early. The convex Lens of rock crystal was found by Layard among the ruins of the Palace of Nimrod. Seneca describes hollow spheres of glass filled with water as being mainly used as magnifiers. It is practically certain that 
the perfect gem cutting of the Ancients could not have been attained without the use of magnifiers.

In the Book "Essays on the Microscope" by George Adams, Mathematical Instrument Maker to His Majesty (1787), being " A Practical Description of the Most Improved Microscopes," which was one of the Standard Works at that time, Adams said : "It is generally supposed that Microscopes were invented about the year 1580 , a period fruitful in discoveries. The honour of the Invention is claimed by the Italians and the Dutch; the name of the Inventor appears, however, lost."

With regard to the many interesting facts relating to the early History of the Microscope, two valuable contributions have been made by Dr. Charles Singer, M.D., "Notes on the Early History of the Microscope" read before the Royal Society of Medicine in 1914, and "The Dawn of Microscopical Discovery," before the Royal Microscopical Society in 1915.

In giving the following information I have taken the liberty of freely making use of the valuable Researches of Dr. Singer, who points out that there have been three main epochs in the History of Microscopical Discovery. There was the Pioneer Period, extending to about 1660, the Classical Period, covering half-a-century or more from about 1660, and including the work of the great Microscopists, Hooke, Grew, Malpighi, Leeuwenhoek and Swammerdam, and finally the Modern Period, dating from the Optical Discoveries of Newton.

The earliest microscopical observation known is stated by Dr. Singer to be of Seneca (circa A.D. 63) who in his " Quæstiones Naturales" said that "Letters, however small and dim, are comparatively large and distinct when seen through a glass globe filled "with water."

The properties of curved reflecting surfaces, and even to some extent of Lenses, were known to the ancients, and to some mediæval writers, such as Roger Bacon. The invention of convex spectacles is attributed to Salvino d'Amarto degli Armata, of Florence, and to Alessandro de Spina, of Pisa, about the year 1300, and these aids to vision were familiar to many throughout the fourteenth, fifteenth and sixteenth centuries. During this period the optical properties of Lenses were investigated by the penetrating genius of Leonardo da Vinci (1452-1519) and by the mathematical skill of Maurolico (14941575), while convex spectacles must have been on the nose of many a careful illuminator of manuscripts.

Up to this time Dr. Singer points out there is no single instance on record of these glasses having been used for the investigation of nature and that even the many illuminated manuscripts of the fifteenth and sixteenth centuries, especially of the Flemish school, do not suggest the use of magnifying glasses.

The first illustrated publication, for which there is evidence of the use of a magnifying glass, appeared in the year 1592 at Frankfort, bearing the name of George Hœefnagel (1545-1600). The volume consisted of a series of plates engraved on copper, illustrating common objects of nature, but drawn with exceptional skill and minute accuracy. Some few of these drawings revealed enlarged details which would 
have been hardly distinguishable to the unaided eye. These remark able figures are stated to have been the work of Hœfnagel's son, Jacob (1575).

It must be remembered, however, that the occasional use by a naturalist of a simple Lens of low magnifying power could have but little influence on the advance of knowledge. It was not until the Classical Period with the invention of Lenses of very short focus that the simple Microscope became a valuable means of Research. In the Pioneer Period it was rather the discovery that Lenses could be combined into the Telescope and the Microscope that gave the first stimulus to investigation. These compound instruments were invented about the year 1610 .

\section{0 то 1700 A.D.}

The Dutchman Zacharias, miscalled Jansen, and his son made Microscopes before the year 1619 . It was he who, whilst still a lad, had worked with his father, who was a spectacle maker, and appears to have discovered accidentally the principle of a Telescope by placing two Lenses together in a tube. The invention of the Microscope followed about that time, though the exact date is unknown. In the year 1619, Cornelius Drebbel, of Alkomar, brought a Microscope which was made by the Jansens with him into England and showed it to William Boreel, who was Dutch Ambassador tc France, and eventually to England. It is, however, added that Drebbel's instrument was not strictly what is now meant by the Microscope, but was rather a kind of Microscope-Telescope, somewhat similar in principle to certain apparatus described by $\mathrm{Mr}$. Aepinus in a letter to the Academy of Sciences, St. Petersburg. This was formed of a copper tube six feet in length and one inch in diameter. On the other hand, Dr. C. Singer, in his interesting Paper on "The Historical Aspect of the Microscope," does not think this was the case.

A portrait of Jansen is given in Fig. 3. A photograph is also given of Hans Lipperhey (Fig. 4), who is described as the inventor of the second Microscope, Jansen being referred to as the inventor of the first one, that is of the special type described probably in the beginning of the Seventeenth Century.

Dr. Hooke, the author of the famous "Micrographia" in 1665, described means of utilising small drops or globules of glass in a Microscope, and said that by means of this he had been able to distinguish the particles of bodies not only a million times smaller than the visible points, but even to make these visible whereof millions of millions would hardly make up the bulk of the smallest visible grain of sand; so prodigiously do these exceedingly small globules enlarge our prospect into the more hidden recesses of Nature. Di Torre of Naples also largely made use of these globules for his well-known investigations.

As regards Hooke's Book referred to, it may be interesting to give a facsimile (Fig. 5) of the title page as it appeared in 1665. Hooke was a Fellow of the Royal Society, and a facsimile of his signature as it appears in the famous "Roll Call of Fellows" is given at the foot of the front page, in Fig. 5. 


\section{SIR ROBERT HADFIELD, BART.}

As an interesting example of the examination done by Hooke in 1664 , and simple as this may seem now, I give in Fig. 6 the result of an investigation he carried out on the point of a small needle, which to use his own words, was

made to Tharp that the naked Eye is unable to diftinguifh any of its Parts. This, notwithitanding, appeared before his Microfcope as in the Figure at $a a$, where the very Top of the Needle is thewn above a Quarter of an Inch broad; not round or flat, but irregular and uneven.

The whole Piece we have here the Picture of, (according to the Scale given with it) is little more than the twentieth Part of an Inch in Length, and appeared to the naked Eye exquifitely fmooth and polithed; but, as feen by the Microfcope, what a Multitude of Holes and Scratches are difcovered to us? How uneven ant rough the Surface! how void of Beauty! and how plain a Proof of the Deficiency and Bunglingnefs of Art, whofe Productions when moft laboured, if examined with Organs more acute than thofe by which they were framed, lofe all that fancied Perfection our Blindnefs made us think they had! Whereas, in the Works of Nature, the farther, the deeper our Difcoveries reach, the more fenfible we become of their Beauties and Excellencies.

But to return to the Object now before us; A, B, C, reprefent large Hollows and Roughneffes, like thofe eaten into an Iron-Bar by Ruft and Length of Time, $D$ is fome imall adventitious Body fticking thereto by Accident.

6.6.b. Anew the End where this Imall Piece of Needle was broken off, in order to tuke the better View of it.

As Rarp as a Needle is a common Phrafe, whereby we intend to exprefs the moft exquifite Degree of Sharpnefs; and, indeed, a Needle has the moft acute Point Art is capable of making, however tude and clumfy it appears when thus examined. But the Microfcope can afford us numberlefs Inftances, in the Hairs, Brifles, and Claws of Infects; and alfo in the Thorns, Hooks, and Hairs of Vegetables, of vifible Points many Thoufands of times tharper, with a Form and Polih that proclaim the Omnipotence of their Maker.

Another investigation was carried out by Hooke on the "edge of a razor," and to quote his words,

Figure reprefents the Edge (about half a Quarter of an Inch long) of a very tharp Razor well fet upon a good Hone, and fo placed between the Objeet-Glafs and the Light, that there appeared a Reflection from the very Edge, which is thewn by the: white Line $a, b, c, d, e, f$.

When we fpeak of any thing as extremely keen, we ufually compare it to the Edge of a Razor; but we find, when examined thus, how far from Sharpnefs even a Razor's Edge appears: That it feems a rough Surface, of an unequal Breadth from fide to fide, but fcarce any where narrower than the Back of a pretty thick Knife: That it is neither fmooth, even, nor regular; for it is fomewhat tharper than elfewhere at $d$, indented about $b$, broader and thicker about $c$, unequal and rugged about $e$, and mort even between $a, b$, and $e, f$, though very far in any Place from being really ftraight.

The Side immediately below the Edge, and what the naked Eye accounts a Part of it, $g, b, y, k$, had nothing of that Polim one would imagine Bodies fo fmooth as a Hone and Oil hlould give it; but was full of innumerable Scratches croffing one another, with Lines here and there, more rugged and deep than the reft, fuch as $g, b, y, k, 0$, occafioned probably by fome fmall Duft falling on the Hone, or fome more flinty Part of the Hone itfelf.

The other Part of the Razor $L L$, which had been polifhed on a Grind-ftone, appeared like a plowed Field, full of Ridges and Furrows.

The irregular dark Spot $m, n$, feemed to be a littlc Speck of Ruft; corrofive Juices generally working in fuch a manner.

This Examination proves, how rough and unfeemly (had we microfcopic Eyes) thofe Things would appear, which now the Dulnefs of our Sight makes us think extremely neat and curious: And, indeed, it feems impoffible by Art to give a perfect Smoothnefs to any hard and brittle Body ; for Putty, or any other foft Powder, employed to polifh fuch Body, muft neceffarily confint of little hard rough Particles, each whereof cutting its Way, muft confequently leave fome kind of Furrow behind it. In thort, this Edge of a Razor, had it been really as the Microfcope hews it, would fcarce have ferved to chop. Wood, inftead of having a Man's Beard. 
In the Bibliography accompanying the present Address will be found reference to some of the writings of other early workers with the Microscope. For example, Antony van Leeuwenhoek, born at Delft in 1632, constructed the first practical microscope and established the art of properly grinding and polishing the Lenses.

Leeuwenhoek was offered, and accepted, the post of Chamberlain of the Sheriff of the town of Delft, worth $£ 26$ annually, and held this for 39 years. In February, 1680, he was made a Fellow of the Royal Society. Although he never came to London, the Diploma of Fellowship was sent to him in a silver box, having the Arms of the Society graven on it. An interesting account of his life is given by the President of the Royal Microscopical Society, Professor H. G. Plimmer, F.R.S., in his Presidential Address in 1913.

Leeuwenhoek did wonderful work with his simple or singular Microscope. The largest magnification he obtained was about 160 in one of his Microscopes: his twenty-six other Microscopes varied from 40 to 133 magnifications. With this simple instrument, as Professor Plimmer points out in his address, Leeuwenhoek discovered a new world, in fact new worlds, for us. He saw for the first time Infusoria, Rotifers, and Bacteria. It is interesting to note in this connection that Charles Darwin took no compound Microscope, but only a simple one, with him on his famous "Beagle" Voyage.

So important was Leeuwenhoek's work that I give a portrait of him (Fig. 8).

In the paper "On the Construction of the Compound Achromatic Microscope" by Charles Brooke, M.A., F.R.S., read before the Royal Institution of Great Britain, March 10th, 1854, he states that the first compound Microscopes on record, such as that of P. Bonnani, about 1697, which was placed horizontally, and that of $J$. Marshall in the beginning of the eighteenth century, which was vertical, were furnished with central condensers. In later years the development of the illuminating apparatus has by no means kept pace with that of the ocular portion of the Microscope, though scarcely of less importance in attaining the highest perfection in the vision of microscopic objects.

On the authority of Adams, the first three compound Microscopes were said to be those of Hooke, Eustachio Divinis and Philip Bonnani. An account of Divinis' Compound Microscope was read before the Royal Society in 1668 (Philosophical Transactions No. 42).

It must be borne in mind, too, that the progress made in the science of Optics was largely aided by the great work of Sir Isaac Newton, Delavel and Herschel.

\section{0 то 1800 A.D.}

It is stated by Roberts-Austen also in his "Metallurgy" that the Microscope was first applied to the Examination of Iron and the first records go back to 1722 when Réaumur described the structure of Chilled Castings under the Microscope. François in 1832 took 
the inueresting case of the direct reduction of Iron from its Ores, and followed the successive changes by the aid of the Microscope. RobertsAusten also claims that: "If to these analytical data observations under the Microscope with a magnification of 300 to 400 diameters be added, it is seen that ordinary Iron is merely a metallic network with a close-grained tissue, with submerged scoriaceous opaline, sometimes subcrystalline, portions, and with little globules and metallic grains ranged in every direction. Sometimes nests of translucent prismatic and bacillary crystals, with metallic portions adhering, are noticed hidden in the paste. These are the grains of Steel which can be made to disappear by heating."

Roberts-Austen thought that Modern Metallography owed some of its development to the use made of it in the Study of Meteoric Irons, also that it is quite possible, as has often happened in the History of Science, that there are several independent origins.

\section{From 1800 A.D. Onwards.}

It is interesting to note that in 1808 , Widmanstätten oxidized a heated specimen and took polished sections of meteoric iron, thus originating what is now termed "Metallography."

Sorby in 1856 founded Petrography, employing sliced sections in connection with the Microscope for the study of rocks, the structures of which are in some cases analogous to those of metallic alloys. In the year 1864 he made an examination of meteoric iron, also studying various metallurgical products; while in 1885 he discovered Pearlite. When Sorby proposed for the first time to submit a specimen of rail, which had broken and caused an accident, to a microscopic analysis, he was told that it was an insane idea. Sorby's method has since been invaluable for this very purpose-in fact in this Country and in America and elsewhere tens of thousands of photomicrographs have been prepared in connection with the investigation of broken and other rails.

Mr. J. Stuart-himself a veteran of some eighty-four yearsof the Clapham Common Optical Works of Messrs. Ross, told me recently that in the 'seve: ties of the last Century he had repeated visits from Dr. Sorby, who brought various specimens of Steel for examination under the Microscope. Mr. Wenham, Vice-President of the Royal Microscopical Society and the Inventor of the Binocular Microscope, as well as of other microscopical apparatus, was at that time working with Messrs. Ross as their Scientific Adviser. Mr. Wenham was also interested in the study of the structure of steel and had many conversations with the late Dr. Sorby, in fact, constructed for him a high power Binocular which Mr. Stuart believes was the first to be used in connection with the examination of Steel.

Incidentally it may be useful to refer to the fact that the invention of the Oil Immersion Objective was not, as is often imagined, of foreign origin, but was originated by Mr. Wenham in 1870, that is, six or seven 
years before Oil Immersion Objectives were constructed at Jena by Professor Abbe. In a Paper read by Mr. Wenham, entitled "Remarks on High-power Definition," at a meeting of the Royal Microscopical Society in June of that year 1870, he says: "Of course there is no optical advantage attendant upon the use of water in immersion lenses. If a medium of the same refractive power as the glass were to be employed the result would be better. Water, having a low refractive index, an adjustment is required for each thickness of cover, and a difference of adjustment is not so marked and sensitive as in the ordinary dry objective; but if a medium of similar refraction to the glass were to be used, no adjustment would be required for any thickness of cover, supposing the test objects to be mounted thereon (which they generally are), for, in fact, we should then view them all with a front of the same thickness-considering the cover, the front lens and the interposing medium as one."

In addition to reading this Paper, Mr. Wenham exhibited at the same Meeting an Oil Immersion Lens using Cedar Oil and an illuminated object showing great brilliancy. It appears, however, he did not at the time realise that his Oil Immersion could have yielded the great numerical aperture which it afterwards gave in the hands of Professor Abbe.

Another interesting point is the fact that Andrew Ross, the founder of the firm of Messrs. Ross, discovered the system of the Collar Adjustment for Water Immersion Lenses and that Mr. Wenham was the Discoverer of the Oil Immersion which required no Collar Correction.

To show how little was thought of the Microscope as a scientific instrument in connection with the study of Iron and Steel, reference may be made to a Book which I have often found useful, namely, Ferdinand Kohn's "Iron and Steel Manufacture," published about 1868 and based upon a series of valuable articles on " The Manufacture of Iron and Steel," which appeared in "Engineering." In this book Kohn says, in the chapter devoted to "Steel under the Microscope," "An experienced steelmaker can estimate very closely the ferrous quality, chemical composition, tensile and compressive strength of any sample of steel, and even the mode of treatment which it has undergone, by looking at its fracture under the Microscope."

It appears, however, this only meant a small hand Microscope. The following are the words: "A Pocket Microscope of this kind ought to be the companion of every man interested in Steel or Steel Manufacture. Lenses of the usual kind, even if piled up in sets of three or four, are entirely insufficient. The Lens must be of a very small focus, and properly achromatic. A little practice is sufficient to enable the user to "see" through this Lens; but it is, of course, not quite so easy to learn the meaning of what is seen, and to estimate from the appearance the quality of the steel inspected."

Special reference was made to some investigations then being carried out (1868) by Mr. Schott, the Manager of Count Stolberg's Foundry at Islenburg, upon the appearance of liquid and solidifying Cast Iron under the Microscope. Mr. Schott contended that each 
crystal of iron is a double pyramid upon a flat square base, and that the ratio of height to base of the pyramid is proportional to the carbon content. In Cast Irons and hard Steel the crystals approach the cubical form, whilst in Wrought Iron the pyramids are almost flattened down into leaves. In addition the quality of a steel is shown by the arrangement of the crystals. The highest quality of steel has its crystals in parallel positions with their axes in the direction of the pressure exerted on them in working. An examination of the fracture of a good steel in reflected light shows a series of parallel streaks on the surface, whereas in a bad steel several systems of "parallel lines can be seen.

The presence of segregated material and size of the grain can also be seen under the Microscope. The absence of the former and the fineness of the latter indicate good material.

The qualities of parallelism of the material and fine grain seem to be due to different causes. The former seems to be caused by the action of heat, and repeated melting is the great panacea in this respect, whilst the latter is brought about largely by working the material; on the other hand working the material seems to prove that parallelism and high temperature bring about the coarsening of grain.

Singular to say, Kohn does not make a single reference to the work of Sorby, which was evidently then only known by few people.

Dr. Dallinger, F.R.S., who resided many years in Sheffield, gave in the Journal of the Royal Microscopical Society, Vol. 17, 1877, page 224 , a "Note on the Ultimate Limit of Vision" as applied to modern Microscopical Lenses. He reasoned that mathematicians of the first order, notably Helmholtz, had concluded that the limit of vision had been reached and that the Optician could practically give no further aid. Dr. Dallinger considered that the limit marked out was about the one-hundred-and-eighty-thousandth of an inch, and added that he did not consider the limit of visibility had been reached.

Dr. Sorby in a Paper on the "Limit of the Powers of the Microscope" to the same Society in $\mathbf{1 8 7 5}$ referred to an experiment of Dr. Royston-Pigott which showed that the smallest visual angle he could ever distinctly appreciate was a hole $1 \frac{1}{4} \mathrm{in}$. in diameter at a distance of 1,000 yards, which corresponds to about 6 seconds of arc. This visual arc in a Microscope magnifying 1,000 linear would correspond to about three-millionths of an inch.

Tchernoff took up the study of crystallization of Steel, his work being brought before this Country by the late Sir William Anderson. In 1878 Wedding studied Steel by the aid of the Microscope. The work of these investigators caused rapid increase of interest in this subject.

Dr. Martens of Berlin rendered further valuable services, in fact was one of the first to introduce the practical study of Iron and Steel by Metallography. Martens' work commenced about 1878, when he published notes on the Microstructure of Steel. 
In 1880 the use of the Microscope was introduced at Le Creusot Works, and important investigations by Professors F. Osmond and J. Werth were started, and from that date were carried out on the lines first indicated by Dr. Sorby.

In his Book on "How to Work with the Microscope," 1880 edition, Dr. Lionel S. Beale, F.R.S., a former President of the Microscopical Society, gave an interesting statement as to the methods of preparing specimens when examining the Microstructure of Iron and Steel.

Roberts-Austen in his book already quoted does just credit to the important work carried out in this Country by Professor J. O. Arnold, F.R.S., who had the great advantage of being in touch and collaborating with the late Dr. H. C. Sorby -in fact the mantle of Sorby descended upon him. Arnold commenced his work about 1890, and the World is under a debt of gratitude for the important results obtained by his valuable labours in this field of research.

Professor Arnold tells me that his first association with Sorby was about 1885 at the Natural Science Section of the Literary and Philosophical Society in Sheffield, where I also met him. When Arnold was appointed to the Chair of Metallurgy in the University of Sheffield in 1889 he persuaded Sorby to resume his micrographic work on Steel in conjunction with his (Arnold's) work on Chemical Analysis, Recalescence and Mechanical Testing, feeling sure that micro work was a vital factor, necessary to render more complete our knowledge of steel. However, Sorby stated he had so much on hand, and his eyesight was failing, that he was not able to take up the work again, but how glad he was to find that his pioneer work was considered to be helpful to Metallurgy. Sorby lent Arnold all his pioneer sections during his lifetime and in his Will left them to the Metallurgical Department of the University of Sheffield. Sorby also gave Arnold h!s various data and, on several occasions, went through his different sections, which, singular to say, were afterwards destined to be Arnold's for eleven years. Through the kindness of Professor Ripper these specimens are exhibited this evening.

It may be added that Sorby discovered at least five constituents of Steel, Stead three, and the Sheffield University-largely the work of Arnold himself-was responsible for many of the others now known to the World. It was also Arnold who determined the quantitative composition of Sorby's Pearlite and Hardenite.

Dr. J. F. Stead, F.R.S., also at an early date saw the great importance of this branch of investigation, and by his lucid papers and research work has greatly aided the progress of Metallography.

Osmond's unrivalled research work further established modern Metallography in 1895. He discovered successively the constituents of Quenched Steel and accurately determined the critical points of Iron. Moreover he had, along with Werth, previously described the cellular structure of metal. As Sauveur says, if Sorby was the pioneer of Metallography and Tchernoff its father, Osmond has been its torch-bearer.

The work of the Nomenclature Committee on Metallography is useful to those interested in this subject, and will be found in Vol. I 
of the Iron and Steel Institute Journal, 1902, comprising some twentythree pages in its Glossary of Terms.

In addition to the main Societies, who have assisted in developing Microscopy, have been the following: The Sorby Scientific Society, comprising The Sheffield Microscopical Society, and The Sheffield Naturalist's Club, which were amalgamated on January 1st, 1918; the Quekett Microscopical Club; the Dublin Microscopical Club, and the Photomicrographic Society.

Special reference may be made to the excellent work of the Quekett Club, which is probably the most active Microscopical Club in any Country. Its Headquarters are in London, and Meetings are held from time to time. The present occupant of the Presidential Chair is Dr. A. B. Rendle, M.A., F.R.S.

\section{SECTION III.-MODERN WORK ON MICROSCOPES, OBJECTIVES AND EYE-PIECES.}

Mr. Conrad Beck, F.R.M.S., many years ago did vallable work on behalf of Microscopy in his Cantor Lectures before the Royal Society of Arts, 1907, on "The Theory of the Microscope." Previous to these Lectures, Mr. John Maynall, junr., gave two excellent series of Lectures on the samc subject, entitled "The History of the Microscope," before the same Society.

An able Address was read by Mr. Joseph E. Barnard, now President of the Royal Microscopical Society, in February, 1919, on "The Limitations of Microscopy." Everyone interested in this subject should read the Address, which is divided into various subjects, dealing with dimensions met with in Microscopy, a discussion on the resolving power and limits of resolution and visibility; also descriptions of the Ultra-Microscope and of experiment sillustrating its use, together with a discussion of the advantages of ultra-violet light in ordinary Microscopy; and finally suggestions as to future lines of Research.

As this paper points out, the limit of resolution may be said to have been reached when it is not possible to distinguish the details of the specimen uncler examination. The limit of visibility is, however, lower than this, for, although no detail can be seen, the specimen can be made visible as a spot in the field of view.

The question of Resolution is touched upon, from which it appears that under the most favourable circumstances, the practical limit is reached when objects in a row are about $\cdot 20$ micron $(1 / 50,000 \mathrm{~cm}$.) apart. If the body is less than this size under the best microscopic conditions now available no detail can be distinguished.

The Ultra-Microscope shows the presence of much smaller dimensions than those mentioned above, that is, as bright specks on a dark background, but it shows none of the internal features, and no matter what the shape or nature of the object under view, it always appears circular. The smallest particle observable, that is, in the UltraMicroscope, is that of colloidal gold, about 5 micromillimeters $(1 / 2,000,000 \mathrm{~cm}$.) in diameter. Thus the Ultra-Microscope can distinguish particles about forty times smaller than those which can be resolved under the ordinary Microscope. 
Mr. Barnard showed in his Address that whilst the resolving power of a given instrument depends upon its design, it also depends upon the wave-length of the light used to illuminate the object under examination. Thus, if the object is illuminated with ultra-violet rays greater resolution still can be obtained, but, of course, the results are not directly visible and must be recorded photographically.

In a paper recently read before the Royal Microscopical Society by Colonel J. Clibborn, C.I.E., B.A., on " A Standard Microscope," it was stated by Mr. Conrad Beck that the Manufacturers of Microscopes worked under great difficulty during the War. It was not until after the 11th November, 1918, that any Microscopes were allowed to be made, all the Factories being fully engaged on other Optical Instruments. It is interesting to note, however, that these Firms are now spending large sums in manufacturing tools for the production of Microscopes, many of them to be made under the Specifications brought forward by the Committee on Microscopes appointed by the British Science Guild.

At the recent British Scientific Products Exhibition an excellent set of Exhibits was shown by the British Optical Instrument Manufacturers' Society, Ltd. Some dozen or more of the principal firms exhibited Optical Instruments and Glasses.

As pointed out in the valuable Catalogue of that Exhibition, the Optical Instrument-making Industry originated in most of its Branches in Great Britain. Newton, Young, Faraday, Clerk Maxwell and Rayleigh were the pioneers of Optics. The Achromatic Telescope was invented by Dolland, and the modern form of Achromatic Microscope by Lister. Let us therefore show that we are trying to be worthy successors of these great men.

The Optical Association has published an illustrated booklet on Scientific Instruments, which includes, with a brief description, the name of every known instrument both current and obsolete, together with a key to the British Makers. The Trade has set up a powerful Research Association and has participated in the inauguration of a Scheme of Education in Optical Engineering which is being developed by the Imperial College of Science and Technology at South Kensington. It may be mentioned that the Governing Body of the Imperial College of Science and Technology recognises the importance of Technical Optics in their relation to the needs of the Nation by providing in the Estimates of their new Scheme of Development the sum of $£ 50,000$ for expenditure on Land, Buildings and Equipment, and the

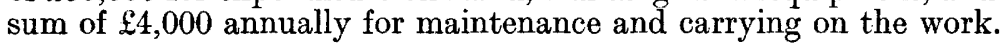

Messrs. Chance Brothers commenced the manufacture of Optical Glasses in England in 1848. During the recent War they increased their output some twenty-fold. They make something like seventy different types of Optical Glasses together with a number of new types which have been recently introduced. They have rendered great service to our Empire.

Professor J. C. McLennan, F.R.S., of the University of Toronto, who was in England during the War, informed me that he had examined the Fluorite from South Africa and found it to be excellent in quality. 
If this Fluorite can be used in the manufacture of Glass suitable for High Power Objectives, then the South African source of supply should be borne in mind. It is also stated that Fluorite exists in Canada, and our Honorary Treasurer, Dr. Robert Mond, is investigating this matter,

The King recently visited the Leicester Works of Messrs. Taylor and Hobson, the famous Lens experts. He there saw the instruments by which vital errors of a few millionths of an inch are avoided, and had explained to him the principles of the use in this connection of light interference, which was first studied by Sir Isaac Newton in Soap Bubbles. This Firm also make the "Aviar" Lens, which through repeated calculations and readjustments of formulæ enabled the British Photographing Aeroplanes to beat the "Archies."

In a recent number of the "Scientific American Supplement" (August 30th, 1919), a statement is made that in spite of the traditional superiority of the German Optical Industry, during the War their Lenses proved distinctly inferior to those of French and English make. The English developed superior Lenses during and under the stress of the War.

In a perfect High Power Objective known as Apochromatic, it is desirable this should give :-

(a) Full Resolution.--The resolution increases with, and is a function of, Numerical Aperture. The number of lines to the inch which an objective will resolve, if perfect, may be calculated from the Numerical Aperture.

(b) Good Definition.-Which could be magnified by a $\times 28$ eye-piece or its equivalent without breaking down.

(c) A Perfectly Flat Field.-This is never actually obtained.

(d) Freedom from Chromatic Aberration:

Achromatic Lenses generally give good definition and their field is often somewhat flatter than in that of the Apochromats. They do not, however, give such good resolution, and are only partially colour corrected. The latter failing makes them much less efficient than the Apochromats for photographic work.

The foreign $2 \mathrm{~mm}$. Objective used in the Hadfield Laboratory is a very good one of its class. Its Numerical Aperture is 1.3, and therefore according to the formula of Professor Abbe, should, if perfect, resolve about 92,000 lines to the inch. I have had photographs taken by it which show 85,000 lines to the inch clearly resolved. Its definition begins to break down with an eye-piece magnification of about 15. For an Apochromat its field is very flat, and it is in this respect chiefly that we found it superior to other Apochromats we examined. Its colour correction is apparently perfect.

It may be added that Messrs. Watsons supplied to the Research Laboratory of my firm a very excellent $2 \mathrm{~mm}$. Objective. 
In fast photomicrographs (btained with it seemed to possess almost equal quality to those from the kest foreign objectives. Fig. 13 is a photomicrograph of a specimen of Steel taken with the above-mentioned foreign $2 \mathrm{~mm}$. Apochromat, whilst Fig. 12 is a photomicrograph of the sams section under exactly similin conditions, taken with the Watson $2 \mathrm{~mm}$. Apochromat. It will be seen that there is very little to choose between the two photographs from the point of view of resolution and flatness of field. There is no doubt that English mekers can, when required. produce Objectives at least equal in quality to the best for eign makes.

\section{SECTION IV.-FERROUS METALLOGRAPHY.}

Several excellent Works have been published on the important subject of Metallography, including "Physical Metallurgy," by Dr. Walter Rosenhain, F.R.S., which has proved of the highest service. No book, too, on the subject has been of greater use in the past than that by Professor Albert Sauveur, of Harvard University, "The Metallography of Iron and Steel." Great advances have been made since the date of its first publication, and in the second edition, 1916, it remains a standard work of reference and a model for books on a special subject -excellent matter, well printed and illustrated. The chapters are divided into Lessons, some twenty-four in all, commencing with the Study of Pure Metals; Pure Iron and Steel, up to High Carbon Percentages; the Effect of Impurities Upon Steel; Close Studies of Thermal Critical Change Points ; the Effect of Annealing, Hardening and Tempering upon both ordinary and Special Alloy Steels, are considered. The Metallography of Cast Iron also receives attention. Various Apparatus for the Metallographic Laboratory, including the study of the Microscope itself, and the Apparatus, Illumination, Sources of Light, Condensers, and Photomicrographic Cameras; a description of the best Methods and Manipulations; also a most excellent nomenclature of the various Microscopic Constituents, including Austenite, Cementite, Martensite, Ferrite, Osmondite, Ferronite, Hardenite, Pearlite, Graphite, Troostite, Sorbite, Manganese Sulphide, and Ferrous Sulphide.

In words which deserve consideration by us all, so I quote them in full, Professor Sauveur in his Introduction and Remarks upon the Industrial Importance of Metallography, points out:

"Invaluable information is given by chemistry without which both the physicist and the metallurgist would be in utter darkness, but this science throws little or no light upon the anatomy of living or inanimate matter. Its very methods, which call for the destruction of the physical structure of matter, show how incapable it is to render assistance in this, our great need.

The parallel drawn here between metals and living matter is not fantastic. It has been aptly mede $\mathrm{ky}$ Osmond, who said rightly that modern science was treating the industrial metal like a living organism, and that we were led to studv its anatomy, that is, its physical and chemical constitution; its biology, that is, the influence 
exerted on its constitution by the various trextments, thermal and mechanical, to which the metal is lawfully subjected; and its pathology, that is, the astion of impurities and defective treatments upon its normal constitution.

Fortunately Metallography does more than reveal the proximate composition of metals. It is a true dissecting method which lays bare their anatomy - that is, the physical grouping of the proximate constituents, their distribution, relative dimensions, etc., all of which necessarily affect the properties. For two pieces of steel, for instance, might have exactly the same proximate composition - that is, might contain, let us say, the same proportion of pearlite and ferrite, and still differ quite a little as to strength, ductility, etc., and that because of a different structural arrangement of the two proximate constituents; in other words, because of unlike anatomy.

It is not to be supposed that the path trodden during the last score of years was at all times smooth and free from obstacles. Indeed, the truth of the proverb that there is no royal road to knowledge was constantly and forcibly impressed on the minds of those engaged in the arduous task of lifting metallography to a higher level.

Its short history resembles the history of the development of all sciences. At the outset a mist so thickly surrounds the goal that only the most courageous and better equipped attempt to pierce it and perchance they may be rewarded by a gleam of light. This gives courage to others, and the new recruits add strength to the besieging party. Then follow the well-known attacking methods of scientific tactics and strategy, and after many defeats, and now and then a victorious battle, the goal is in sight, but only in sight and never to be actually reached, for in our way stands the great universal mystery of nature: what is matter? what is life?

Nevertheless there is reward enough for the scientist in the feeling that he has approached the goal, that he has secured a better point of vantage from which to contemplate it. The game was worth the candle, and if scientific workers must necessarily fail in their efforts to arrive at the true definition of matter, whatever be the field of their labour, they at least learn a great deal concerning the ways of matter, and it is with the ways of matter that the material world is chiefly concerned. Hence the usefulness of scientific investigation, hence the usefulness of metallography."

Among the many workers who have contributed to the progress of Metallography may be mentioned:--Arnold, Benedicks, Belaiew, Brearley, Carp snter, H. Le Chatelier, Campbell, Desch, Edwards, Elliot, Guillet, Gulliver, Giolitti, Hatfield, Honda, Howe, Humfrey, Hudson, Zay Jeffries, Iaw, Martens, McCance, Osmond, Portevin, RobertsAusten, Rosenhain, Robin, Sorby, Sauveur, Stead, Thompson, Werth.

In the valuable Pocket Encyclopædia on "Iron and Steel" by Mr. Hugh P. Tiemann, B.S., A.M., with an introduction by Professor H. M. Howe, some thirty pages are devoted to Metallography. The book contains a most excellent summary of the terms used in this Branch of the Science of Metallurgy, treating of the constitution and structure of Metals and Alloys, also their relation to physical properties. 
Tiemann says that originally the term Metallography concerned principally the visual examination of the structure of metals, and hence was divided into Microscopic Metallography, or, briefly, Micrometallography, where Microscopes were used to secure high magnifications, and Megascopic, Macroscopic or Macro-Metallography, where the naked eye or very low magnifications were used. The terms Microscopy and Micrography are also used.

With reference to Metallographic Examination, Tiemann considers that the methods employed may be classified into :-

(1) Optical Analysis: Determining the Constituents, structures, forms, appearances, etc., by the eye alone or assisted by suitable magnifying devices.

(2) Thermal Analysis: A Study of the nature of metals and alloys by means of heating and cooling curves, changes in specific heat, etc.

(3) MAGnetic AnAlysis: Determination of changes in nature affecting the magnetic properties.

(4) Physical Analysis: Determination of the properties by the usual methods of testing.

(5) Chemical Analysis: Both proximate and ultimate; generally in conjunction with one of the other methods.

He defines the Microscope as follows :-

(a) A simple Microscope is one which has only one Lens or set of Lenses; a compound Microscope has two such systems of Lenses, one near the object (Objective) and the other near the eye of the observer (Eyepiece).

(b) The binocular Microscope consists of two instruments mounted to give a stereoscopic (perspective) view.

As regards the minute nature of matters forming metals and alloys of metals, an interesting statement is made by Mr. Zay Jeffries, D.Sc., Cleveland, U.S.A., who, when speaking of the ageing of the non-ferrous metal known as Duralumin, in his paper on "The Micro-mechanism of the Ageing of Duralumin," says that when it is cooled from $500^{\circ} \mathrm{C}$. in a furnace, globules of $\mathrm{CuAl}_{2}$ large enough to be seen easily with a high power Microscope, are formed. In the same sample, however, some globules are so small as to be hardly distinguishable, and others too small to be resolved are suggested by the non-uniformity of the surface appearance of the section. When it is considered that the smallest globule of $\mathrm{CuAl}_{2}$ resolvable with a high power Microscope contains about 2,000,000,000 molecules, it is evident that with rapid cooling sub-microscopic particles of $\mathrm{CuAl}_{2}$ must be present in large numbers ; in fact, after quenching, the average size of a particle must be submicroscopic. The whole phenomenon of ageing must, therefore, involve changes which cannot be studied directly with a Microscope.

The same author has devoted a great amount of time to the study of grain sizes and their measurement in metals. He has contributed several papers to the Faraday and other Societies in this country. Much valuable information is to be found in the work done by Dr. Zay .Jeffries. 
Preparation of SPecimens and ETChing.-In the preparation of specimens for micro-examination great skill and ingenuity have been displayed by numerous investigators from the time of Sorby onwards.

When it is considered that a maximum magnification has now been reached of about 8,000 , the difficulties to be overcome will be readily recognised. Supposing the surface of one side of a cube, say one twenty-fifth of an inch square, to be under examination, this has meant that the area under observation has been multiplied or magnified to a surface of say $30 \mathrm{ft}$. square, or about 900 square feet. It will be seen how the slightest scratch or groove, imperfect polishing, bad etching, or other defect will at once interfere with the desired results being obtained.

In this connection I should like also to call attention to an interesting Paper read by Sir G. T. Beilby, F.R.S., before the Royal Society in February, 1914, entitled "Transparence or Translucence of the Surface Film produced in Polishing Metals." Some beautiful Photomicrographs are there shown, photographed by a $3 \mathrm{~mm}$. Oil immersion Lens of 1.4 N.A. The thickness of the films covering the slight Pits on a Copper surface was stated by Sir George to be probably of the order of 10 to 20 micro-millimetres $\left(\frac{1}{2,500,000}\right.$ to $\frac{1}{1,200.000}$ inch).

Although if it was possible to get raw surfaces free from all grooves, scratches, and other blemishes, some structure would be developed, it must be remembered that not even the finest polishing will display structure, therefore etching must be employed.

The etching accomplishes two things: it removes the amorphous layer, and then attacks the various constituents differently. The products of the etching attack usually differ in appearance more than the original constituents.

For high power the etching must be very light, that is, the time of etching must be short. A 5 per cent. solution of picric acid in alcohol gives the best results. The perfect flatness of the polished surface must be retained, and only the lightest possible etching is given. In low power work the etching is fairly strong in order to obtain contrast between the light and dark portions.

As regards the effect of different kinds of etching, I invite attention to Photomicrographs, Figs. 9, 10 and 11. These are from a Gun Tube Steel containing .42 per cent. Carbon, .74 per cent. Manganese, and representing material as forged, that is without further 1 reatment.

Fig. 9 was etched with 5 per cent. Picric Acid in Alcohol.

Fig. 10 was etched with 5 per cent. Nitric Acid in Alcohol.

Fig. 11 was etched with 5 per cent. Solution Meta-Nitro-BenzclSulphonic Acid.

The structure shows grains of Ferrite on a ground mass of Pearlite and the Photomicrographs prove that the Structure developed is in lcpendent of the particular etching reagent used. The number of etching reagents might be extended on this work with practically the same results in each case. Most Alloy Steels, for example, Manganese Steels, quenched and tempered, Nickel Chromium and other Steels, 
require extraordinary care in the etching or otherwise the structure will vary considerably and be misleading. Some alloys, for example Steel containing high percentage of Nickel, are not attacked by any ordinary etching reagent.

All honour to Sorby, the man who led the way in this branch of Science, and started us, who are to-day benefiting in such a remarkable manner from the knowledge he first originated and obtained in this important and complex branch of Science. All honour, too, to the band of willing workers who have accomplished such great progress, and who have surmounted the many difficulties in their path.

\section{SECTION V.-STANDARD MAGNIFICATIONS FOR PHOTOMICROGRAPHS.}

The question of the Standardisation of Magnifications for Photomicrographs of Metals and Alloys has been given a certain amount of discussion both in this Country and in America.

Committee E-4 of the American Society for Testing Materials has, in fact, drawn up tentative "Definitions and Rules governing the Preparation of Micrographs of Metals and Alloys," which include Standard Magnifications for general use, and Ferrous and Non-ferrous Metals. I have brought this matter before the British Engineering Standards Association, who are considering the subject. The Institute of Metals in this Country in its "Notes for Authors" also specify certain Standard Magnifications which it is desired Authors should use.

Whilst not wishing in any way to hamper the Research Worker, there are reasons why it seems strongly advisable that for general purposes Standard Magnifications should be adopted for the Photomicrographs. Very little quantitative data is forthcoming from the micro-examination of metals. Where the grain size can be determined, this is often distinctly useful and worth recording. For the most part, however, the Microscopist is dependent on a trained eye, resulting from prolonged experience in the examination of microstructures to aid him in their interpretation. It would seem reasonable, therefore, that the magnifications used should be standardised and as few as possible, in order that compurisons between the structures of different specimens may be facilitated.

I would therefor like strongly to urge that the various Societies interested in Metallography should join in drawing up rules governing the reproduction of photomicrographs, which should be of certain Standard Magnifications and naturally should be reproduced full size.

Surely there is every reason for having an International Standard; at any rate, Great Britain and America could work together. It might well, indeed, be made a matter for Allied consideration, or one for consideration in connection with the movement for the formation of International Unions in which the Conjoint Board of Scientific Societies is interesting itself. 


\section{SECTION VI.-CRYSTALLOGRAPHY.}

As crystallography is, if not directly then indirectly, related to the work of the microscope, I have asked my friend, Dr. A. E. H. Tutton, F.R.S., the eminent crystallographist, to communicate suggestions to this Symposium by way of a Paper or to the Discussion from his point of view.

During the recent Meeting at Bournemouth of the British Association, Miss Nina Hosali, B.Sc. of the University of London, exhibited interesting Models of Crystals. This worker has most kindly submitted her collection this evening and I am sure they will be found useful.

As explained by Miss Hosali, the object of these models is to illustrate :-

(a) The forms possible to crystals.

(b) The different kinds of symmetry possessed by these forms.

(c) How the forms are referred to crystallographic axes.

Each model illustrates one of the thirty-two classes of symmetry, and represents several crystal forms correctly orientated with regard to crystallographic axes, the latter being shown by black threads. A model consists in the first place of a glass envelope whose shape is hat of some simple crystal form, and within this envelope two or three other forms are represented by means of coloured silk threads stretched over frameworks of thin copper wire. By this means it is easy to make the forms intersect if necessary, and they are readily distinguished from one another by the use of differently coloured threads.

The symmetry elements of the class represented by any model are shown as follows :--

(a) The traces of the Planes of Symmetry on the Glass envelope are shown by steel wires.

(b) Axes of Symmetry are shown by white threads.

The set of 24 models exhibited represents 21 out of the 32 classes and over 70 different forms. In many cases different varieties of the forms may be produced by rotating or inverting the models, or by reflecting them in a mirror, and when these modifications are taken account of, the number of the forms shown is brought up to about 140 .

It may be interesting to add that there has been recently developed and described by the Research Committee of the American Society of Mechanical Engineers an instrument called the Microcharacter (from the Greek-to engrave or scratch on a small scale). This instrument determines that characteristic of a crystal which is the combination of three of the five fundamental conceptions of hardness, namely, the combined effect of cutting, scratch, and penetration hardness. It can be employed for determining the hardness of the micro-constituents of steel and should be very useful to the Metallographist. This Apparatus should be very useful to the Metallographer, as the 
point used is practically sharp under a magnification of no less than 2000 diameters. By this method these combined characteristics can be obtained for any individual crystal, a point of great importance.

\section{SECTION VII.-THE ULTRAMICROSCOPE.}

Much study has been given to the Ultramicroscope, which was introduced about the year 1905 by Siedentopf and Zsigmondy.

In an article which appeared in "The Scientific American," October 2nd, 1915, it was stated that the limits of microscopic observation with direct illumination is about $\frac{1}{4,000} \mathrm{~mm}$. and with oblique illumination by means of violet rays and with the aid of monobromated naphthalene immersion $\frac{12}{100.000} \mathrm{~mm}$. The observation of particles below this may be termed ultramicroscopic. According to Siedentopf, particles may be perceived which have a diameter of about $\frac{4}{1,000.000}$ to $\frac{6}{1,000.000} \mathrm{~mm}$. These are magnitudes which approach very closely to molecular dimensions of complicated compounds, in some cases even attain them.

According to O. E. Meyer, the molecule of Hydrogen has a diameter of $\frac{1}{\mathbf{1 0 . 0 0 0 . 0 0 0}} \mathrm{mm}$., while according to Jaeger, the molecule of $(a)$ ethyl-alcohol has a diameter of $\frac{5}{\mathbf{1 0 . 0 0 0 . 0 0 0}} \mathrm{mm}$.; (b) chloroform has a diameter of $\frac{8}{10,000,000} \mathrm{~mm}$. According to Lobry de Bruyn, the molecule of starch has a diameter of $\frac{5}{1,000.000} \mathrm{~mm}$. Consequently the molecule of starch must be within the 1each of ultramicroscopic perception.

The investigator has therefore before him, subject to increased intensity of light and dark field, the possibility of seeing molecules which seemed beyond reach of human sight, and the hope of following the play of their attractive and repellant forces. The brightness of ultramicroscopic particles begins to decline with the 6th power of the diameter.

If it should prove possible to obtain this deeper insight into the form and structure of matter, a positive service will be done to philosophy permitting of the observation of particles which were formerly far below the limits of ordinary microscopic observation. If the methods which it renders possible can be extended and applied to Metallurgy, then the Metallurgist will doubtless be possessed of still further means to enable him to advance further our knowledge of the structure of metals and their alloys.

\section{SECTION VIII.-CONCLUSION.}

I must now bring these remarks to a close. The subject is a fascinating one, and it has been a labour of love to trace the History of the Microscope and its great development into the wonderful Scientific Instrument of to-day, capable of resolving even over 100,000 lines per inch. 
If Sorby could have been with us this evening it would be a special satisfaction to him to see the child of his brain grown to the giant it now is, I mean in the application of the Microscope to the examination of Metals and their Alloys. In a separate communication entitled "The Great Work of Sorby, of Sheffield," I have dealt briefly with his Researches in this field.

In addition to this present Address, I am contributing to the Symposium a Paper on the Faraday Society and its Work; also jointly with Mr. T. G. Elliot, F.I.C., a Paper on "Photomicrographs of Steel and Iron Sections at High Magnification," as well as a Bibliography from 1665 down to the present time, which although not claimed to be complete may be found useful to those interested.

I trust that in each of these contributions will be found some information that may be of interest and give encouragement to pursue our Researches in this valuable field of Scientific Investigation. 